\title{
SPECTRAL CLASSIFICATION AND
}

\section{MULTICOLOUR PHOTOMETRY}

Edited by C. FEHRENBACH and B. E. WESTERLUND
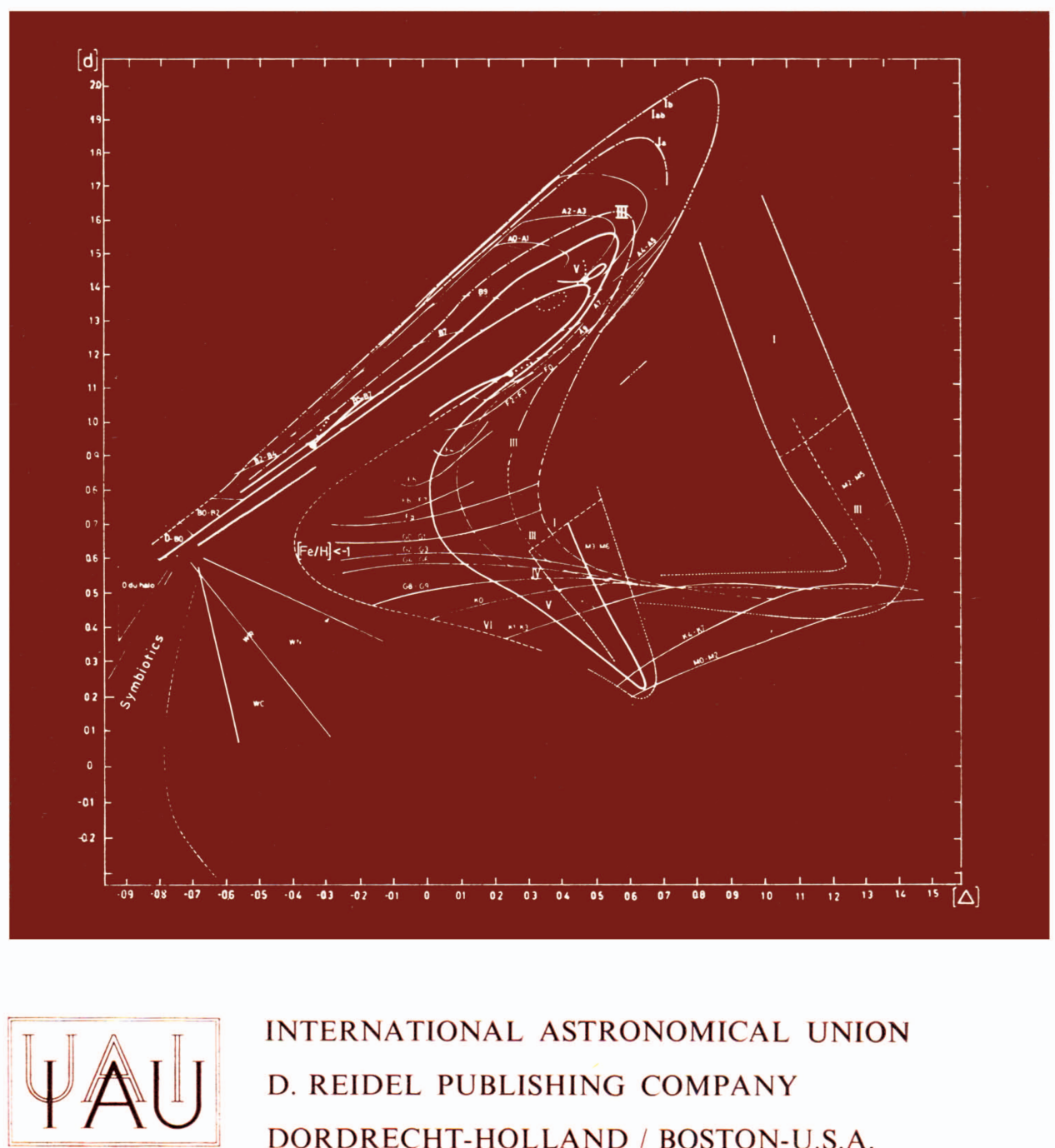

INTERNATIONAL ASTRONOMICAL UNION

D. REIDEL PUBLISHING COMPANY

DORDRECHT-HOLLAND / BOSTON-U.S.A. 
SPECTRAL CLASSIFICATION

AND

MULTICOLOUR PHOTOMETRY

SYMPOSIUM No. 50

This is the first symposium dealing with Spectral Classification since I.A.U. Symposium No. 24 in Saltsjöbaden in 1964.

Forty-six participants from fourteen countries attended the meeting, where fifty papers were presented. Four introductory lectures dealt with: classification of slitspectra; classification of objective-prism spectra; photometric classification; and catalogues and documentation. In the three sessions on classification particular interest was shown in criteria for identification and classification of supergiant stars, peculiar stars, cool stars, and Population II stars as well as in the interpretation of the data. The possibilities of automatic classification of objectiveprism spectra were discussed extensively. In the last session the main topic was the problem of making existing and forthcoming spectroscopic and photometric data easily available, as catalogues and/or data centres.

Audience:

Professional astronomers. 
SPECTRAL CLASSIFICATION AND

MULTICOLOUR PHOTOMETRY 


\title{
INTERNATIONAL ASTRONOMICAL UNION
}

UNION ASTRONOMIQUE INTERNATIONALE

SYMPOSIUM No. 50

HELD IN VILLA ĆARLOS PAZ, ARGENTINA, OCTOBER 18-24, 1971

\section{SPECTRAL CLASSIFICATION AND MULTICOLOUR PHOTOMETRY}

\author{
EDITED BY \\ CH. FEHRENBACH \\ Observatoire de Haute-Provence, Saint-Michel l'Observatoire, France
}

AND

B. E. WESTERLUND

European Southern Observatory, Santiago de Chile

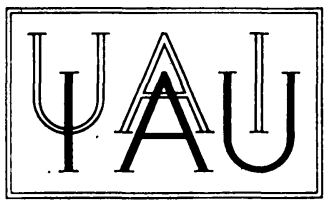

D. REIDEL PUBLISHING COMPANY

DORDRECHT-HOLLAND / BOSTON-U.S.A.

1973 


\author{
Published on behalf of \\ the International Astronomical Union \\ by \\ D. Reidel Publishing Company, P.O. Box 17, Dordrecht, Holland
}

\author{
All Rights Reserved
}

Copyright $\mathbb{0} 1973$ by the International Astronomical Union

Sold and distributed in the U.S.A., Canada, and Mexico

by D. Reidel Publishing Company, Inc.

306 Dartmouth Street, Boston,

Mass. 02116, U.S.A.

Library of Congress Catalog Card Number 72-87471

ISBN 9027702802

No part of this book may be reproduced in any form, by print, photoprint, microfilm, or any other means, without written permission from the publisher

Printed in The Netherlands by D. Reidel, Dordrecht 


\section{PART I/CLASSIFICATION OF SLIT SPECTRA}

PH. C. KEENAN / The Role of Classification of Slit Spectrograms (Introductory Lecture)

R. F. G AR R ISON / Spectroscopic Criteria for the Classification of Peculiar B-type Stars with Colour-Spectrum Discrepancies

R. HER M A N / Classification des étoiles B à partir des raies de l'hydrogène-Comparaison avec d'autres classifications

CH. FEHRENBACH / Etude des étoiles supergéantes du Grand Nuage de Magellan, leurs magnitudes absolues et couleurs

L. DIvAN/Quantitative Spectral Classification in the BCD System for LMC Supergiants

A. ARdeberg, E. MAURICE, and J. RICKARD / Photometric Investigation of IC 2944 (Abstract)

M. F. McCARThy / Spectral Classification Studies of Cepheids Using a Small Telescope with an Image Tube Spectrograph (Abstract)

L. W. SIMON and W. BUSCOMbe / Spectral Classification of Some Long-Period and Semi-Regular Variables Near Times of Maximum (Read by P. Rybsky)

N. G. ROMAN / Some Notes on Stars Near K0

L. A. MILONE / Spectroscopic Observations of the Sanduleak-Seggewiss Stars (Abstract)

C. JASCheK and M. JASCheK / On the Precision of the MK Spectral Classification System

w. GLIESE / On the Accuracy of Spectral Classifications of Main-Sequence Stars

J. S. LANDI DESSY / Problems in Spectro-Photometrical Classification of Late Type Stars (Paper not Submitted)

F. SPITE / Advantages and Limitations of Quantitative Spectral Classification (Read by E. Maurice) 


\section{PART II / CLASSIFICATION OF OBJECTIVE-PRISM SPECTRA}

C. B. StePhenson / Introductory Talk for Session on Objective Prism Spectral Classification (Introductory Lecture)

N. HOUK and A. COWLEY / Two-Dimensional Classification of the HD Stars W. P. BIDELMAN, D. J. MacCONNELL, and R. L. FRYE / Early Results from the Michigan Southern-Hemisphere Spectral Survey (Read by C. B. Stephenson) W. C. Seit Ter / The Bonn Spectral Atlas: Part II

E. H. GEYER / The Present State of a Spectral Survey of the Southern Milky Way for Stars Earlier than A5

B. NORDSTRÖM and A. SUNDMAN / Objective Prism Spectral Classification at the Stockholm Observatory

E. K. KHARADZE and R. A. BARTAYA / The Peculiar Stars and Spectral Classification (Read by B. E. Westerlund)

K. NANDY and P. SMRIGLIO / Spectrophotometry of M and C Stars (Abstract and Summary)

P. M. R Y BSK I / The Spectral Classification of Southern Carbon Stars

R. M. WEST / Automatic Classification of Objective Prism Spectra

K. M. YOSS / Microphotometry-Computer Classification of Objective-Prism Spectra

A. Cassatella, P. MAfFei, and R. Viotti/Blue-Infrared Narrow-Band Photometry from Objective Prism Spectra (Read by L. Gratton)

J. V. CLAUSEN / Preliminary Investigation of Quantitative Spectral Classification by Means of Objective-Prism Spectra Obtained with the Broerfelde Schmidt Telescope (Read by R. M. West)

\section{PART III / PHOTOMETRIC CLASSIFICATION}

B. STRÖMGREN / General Remarks on Quantitative Spectral Classification (Introductory Lecture)

M. GOLAY / Applications of the $U B_{1} B_{2} V_{1} G$ Photometric System

S. C. MORRIS, G. HILL, G. A. H. WALKER, and H. I. B. THOMPSON / Classification of Early Type Stars on the Dominion Astrophysical Observatory Photometric System

R. D. MCCLURE / The David Dunlap Observatory (DDO) Photometric System for Classification of Late-Type Stars

W. OSBORN / Results from Three Dimensional Spectral Classification of Population II Stars Using the DDO Photometric System

V. STRAIŽYS / Photometric Classification of Stars in the Vilnius Observatory

D. L. CRAWFORD / Photometric Classification of B-Type Stars

CH. L. PERRY / Multicolor Photometry of the Galactic Cluster NGC 2362

A. FEINStein / Photoelectric Measures of $\mathrm{H} \alpha, \mathrm{H} \beta$ and $\mathrm{H} \gamma$ in Early-Type Stars

E. E. MENdozA V. / Narrow Band Photometry of Supergiant Stars (Abstract) 
R. F. WING / New Standards for the Spectral Classification of M Dwarfs

K. NANDY / The Identification of T Tauri-Like Stars by Multicolour Photometry

U. W. STEINLIN / Classification of Population II Stars in the $R G U$ System

A. G. DAVIS PHILIP/Photometric Classification of Blue Horizontal-Branch Stars

J. A. GRAHAM and A. SlettebaK/Some Blue Stars of Peculiar Type in the Region of the South Galactic Pole

M.-N. PER R IN / Quelques sous-naines dans la direction du Grand Nuage de Magellan

A. GUtiérReZ-Moreno and h. Moreno / Two Dimensional Spectral Classification of Early Type Stars by Low Dispersion Spectrophotometry

H. MORENO / Low Dispersion Spectrophotometry of Late Type Stars

\section{PART IV / CATALOGUES AND DOCUMENTATION}

C. JASCHEK / Information and Catalogues (Introductory Lecture)

B. HAUCK / Photometric Data in Machine-Readable Form

W. P. Bidelman / Remark in Regard to Bidelman's Data-Bank Project (Read by C. B. Stephenson)

J. Stock and H. Wroblewski / The Southern Objective Prism Survey ( $A b$ stract)

J. Stock and W. OSBORN / A Method for Determining Radial Velocities from Objective Prism Plates

A. ARDEBERG, J. P. BRUNET, E. MAURICE, and L. PRÉ Vot / Spectral and UBV Data for 583 Stars (Supergiants and Foreground Stars) in the Direction of the Large Magellanic Cloud (Abstract)

A. G. DAvis PHILIP / A Study of Interstellar Reddening at High Galactic Latitudes

K. HARAMUNDANis / The Construction and Documentation of the Celescope Catalog 